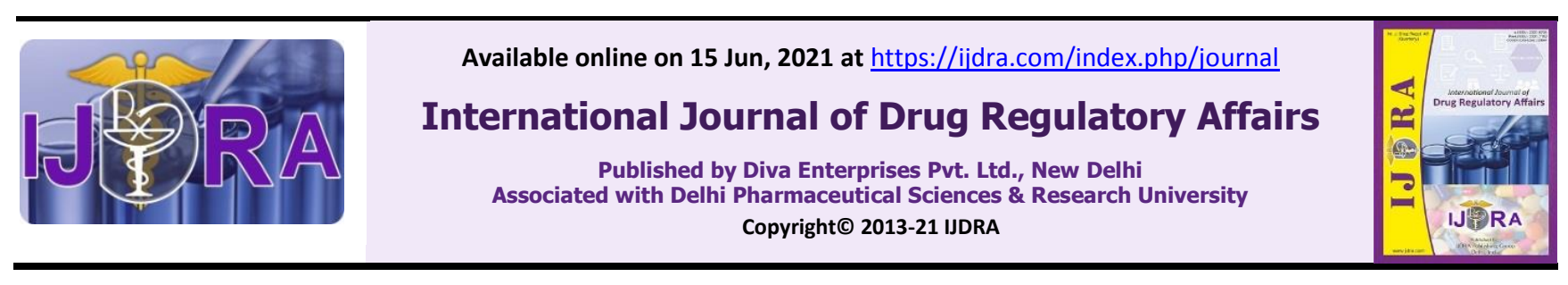

Review Article

OpenOAccess

\title{
Regulatory advances and prospects of variation filing for the registered parenteral products in USA and Europe
}

\author{
Rajdeep G. Makwana, Kuldeep V. Desai, Vaibhav Kikani, Maulikkumar D. Vaja * \\ Saraswati Institute of Pharmaceutical Sciences, Dhanap, Gandhinagar, Gujarat, India 382355
}

\begin{abstract}
Drug Regulatory Affairs (DRA) is a vital unit in a pharmaceutical company. It is concern about the healthcare product lifecycle, it provide strategic, tactical and operational direction and support for working within regulations to expedite the development and delivery of safety and efficacy in pharmaceuticals, veterinary medicines, medical devices, cosmetics and complementary medicines, healthcare products to individuals around the world. Regulatory affairs (RA) professionals are employed in pharmaceutical industry, government, academic research and clinical institutions. As India is growing very rapidly in pharmaceutical sector, there is a need of regulatory affairs professionals to cater the current needs of industries for the global competition. Regulatory affairs professionals are the link between pharmaceutical industries and worldwide regulatory agencies. A regulatory affair is a somewhat new profession which has developed from the desire of governments to defend public health. Substantial documentation and data are required in these types of submissions, resulting in large, complex applications. Today 35 member countries along with 11 candidate countries and 4 international agencies have joined together to create the Pharmaceutical Inspection Cooperation Scheme (PIC/S) to promote a globally accepted GMP. Current constrain of Regulatory Affairs reveals diverse countries need to follow different regulatory requirements for marketing authorization Application (MAA) approval of new drugs. In this present exertion, study expresses the drug approval process and regulatory requirements according to US Food and Drug Administration (UDFDA), European Medical Agency (EMA) and Central Drug Standard Control Organization (CDSCO).
\end{abstract}

Keywords: Parenteral products, Variation filing, Regulatory advances, USFDA, EMEA, MAA, CDSCO, PIC/S

Article Info: Received 20 May. 2021; Review Completed 09 Jun. 2021; Accepted 13 Jun. 2021

\section{Cite this article as:}

Makwana RG, Desai KV, Kikani V, Vaja MD. Regulatory advances and prospects of variation filing for the registered parenteral products in USA and Europe. Int J Drug Reg Affairs [Internet]. 2021 Jun 15 [cited 2021 Jun 15]; 9(2):52-65. Available from:

http://ijdra.com/index.php/journal/article/view/470

DOI: $10.22270 /$ ijdra.v9i2.470

*Corresponding author

\section{Introduction}

\section{Current Global market trend of Pharmaceutical Industries}

In current scenario, for any type of changes in registered parenteral products in any country it is necessary to comply with the regulatory requirements of that particular country.

The pharmaceutical industry is one of the highly regulated industries, with many rules and regulations enforced by the government to protect the health and well-being of the public. Therefore, the aim of the pharmaceutical industry is to identify and develop a generic drug product which can be tailor made to meet the diverse market requirements. As per global market trend, it is estimated that approximately $\$ 150$ billion worth of drugs will be off-patented during the period 2010 to 2017, which will serve as a platform for pharmaceutical companies to develop generic drugs. The pharmaceutical industry in India has shown a remarkable growth which in turn has raised the economy of India. After the introduction of the product patent regime in India, there was a need for pharmaceutical companies both in India and abroad to explore newer markets. Indian pharma majors are entering new markets with global ambitions, mergers and acquisitions. For sustained growth over the next few decades, firms have to concentrate on generic drug products. Government has the responsibility to protect their citizens. It is the responsibility of national governments to establish regulatory authorities with strong guidelines for quality assurance and drug regulations in the respective territories. Efforts to harmonize various elements of drug regulatory activities have been initiated by various intergovernmental organizations at regional and interregional level in the past decade. The driving force behind these efforts has been the increase in global trade in pharmaceutical products, and growth in the 
complexity of technical regulations related to drug efficacy, safety, and quality.

The Pharmaceutical market based on the diversity in the regulation region and marketing interest can be divided into two groups: Regulated and emerging markets. The regulated market involves those countries where there are defined regulatory requirements set by the regulatory bodies of that country and the emerging market countries are those who still lag behind in putting forward the well-defined regulations for drugs. United States (US) and the EU are the biggest and the most potential markets for Pharmaceuticals in the world and are categorized under the regulated markets, whereas ROW (Rest of the World) market includes all the emerging markets like Brazil (LATAM), Tanzania (Africa), Russia (CIS), Hong Kong (ASIA), etc. (1-3)

\section{Regulatory Affairs}

Regulatory Affairs is a comparatively new profession which developed from the desired of governments to protect public health by controlling the safety and efficacy of products in areas in including pharmaceuticals, veterinary medicines, medical devices, pesticides, agrochemicals, cosmetics and complementary medicines.

Regulatory Affairs is key to all stages of product development, so a broad understanding of the complete drug development process may be regarded as a prerequisite to consideration of regulatory strategy leading to successful product approval, in addition to a good understanding of the regulations governing medicinal products.

The Regulatory Affairs carries out a range of assessment and monitoring activities to ensure compliance of Regulatory Requirements of various countries. (4)

"In an ideal world, the need for analysis should be driven by the desire to assure the quality of drug products. However, in the real world the need for pharmaceutical analysis is driven largely by regulatory requirements."

The Indian Pharmaceutical industry is one of the fastest growing industries in India, with a compounded annual growth rate (CAGR) of over $13 \%$ in last 5 years and it is expected to grow at a higher rate in coming 10 years. It is valued at $\$ 8.0$ billion approximately and ranks 4 th in terms of volume and 13th in terms of value globally 2 . All companies engaged in $R \& D$ worth its salt has an individual RA department to aid them in new product development.

The Regulatory Affair's mission is the consistent growth of the company and to elaborate company's market share by - To providehigh quality guidance onevaluation of medicinal products, to advice on research and development of products, and to provide useful and clear guidance on Post Approval Changes.

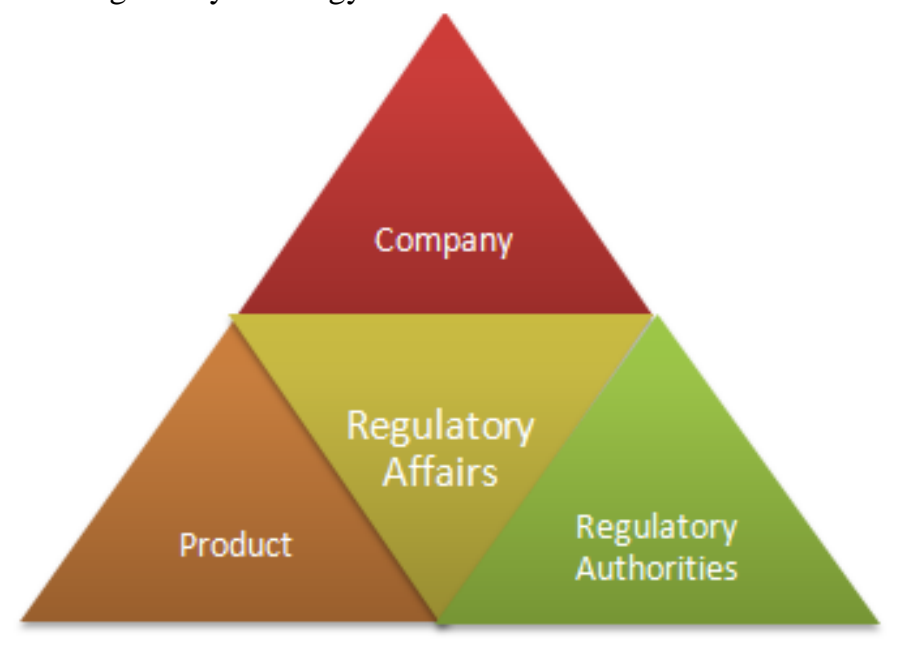

Figure 1. General Regulatory Affairs personnel

\section{Responsibilities}

The responsibilities of RA personnel in general can be summarized into three:

(i) Ensuring that their companies comply with all of the regulations and laws pertaining to their business.

(ii) Working with federal, state and local regulatory agencies and personnel on specific issues affecting their business.

(iii) Advising companies on the regulatory aspects and climate that would affect their proposed activities.

In marketing organization their prime responsibilities involves preparation and presentation of registration documents to regulatory agencies and carrying out all discussion to obtain and maintain marketing authorization (MA) for the products concerned. They need to keep track on ever changing legislation in all countries where the companies is looking to market their product. They play a pivotal role in facilitating the commercial progression of new health products and technology through product life cycle.

Main responsibilities of R.A. department are outlined below:

- Compilation, review and submission of registration dossiers in various countries

- Filing of variations and post-approval changes

- Responding to regulatory related queries from different regulatory agencies and query compliance.

- Providing regulatory feedback to the R \& D team 
- $\quad$ Providing regulatory support to the plant functions

- Managing international regulatory inspections

- Creating regulatory awareness

Contribution of Regulatory Affairs in Pharmaceutical Industry

\section{a. Regulatory Affairs in Product Management}

The key role of RA professional is broader than registration of products, they advise companies both strategically and technically at the highest level. Their role begins right from development of a product to making, marketing and post marketing strategies. Their advice at all stages both in terms of legal and technical requirements help companies save a lot of time and money in developing the product and marketing the same. For countries that do not have their own regulations the World Health Organization guidelines on health matters and World Trade Organization on trade regulations between nations is followed.

\section{b. Regulatory Affairs in R\&D}

The regulatory affairs personnel work hand in hand with marketing and $R \& D$ to develop, innovative products that take advantage of new technological and regulatory developments to accelerate time to market. With new products expected to add significant revenues to the company's bottom lines, small decreases in time to market equate to large material gains in revenue and profit. Employing adaptive clinical trial strategies, obtaining quick approval from regulatory authorities and avoiding pitfalls in processes can accelerate development of new products and help to reduce costly errors and time lags.

\section{c. Changes in regulatory environment}

Guidelines on clinical trials for import and manufacture of new drug were introduced in the Drugs and Cosmetics Rules as Schedule Y in 1998. This heralded the entry of clinical trials organization like Quintiles into India and encouraged the pharmaceutical industry to conduct phase III trials. Ethical Guidelines for Biomedical Research on Human subjects was brought by Indian Council of Medical Research (ICMR) in 2000. Good Clinical Practices were adopted by India in 2001 by Central Drugs Standard Control Organization (CDSCO). The National Institute of Medical Statistics of ICMR also set up a clinical trails registry in 2009. A new amendment to the Drugs \& Cosmetics Act is seeking to replace the Central Drugs \& Services Control Organization (CDSCO) with the Central Drug Authority (CDA) comprising of Drugs Controller General of India as the chairman and five other members. Ten departments will be controlled by the authority include regulatory affairs, imports, new drugs, biotech products, pharmacovigilance, medical devices and diagnostics, organizational services, training, quality control and legal \& consumer affairs. Moreover new bill for regulation of medical devices industry is also in the gambit. Medical Devices Regulatory authority is a body; government is yet to implement to regulate the ballooning medical devices industry whose products are largely approved in other countries and eventually finds entry into Indian market.

\section{Introduction and Overview of International Conference on Harmonisation (ICH) (5):}

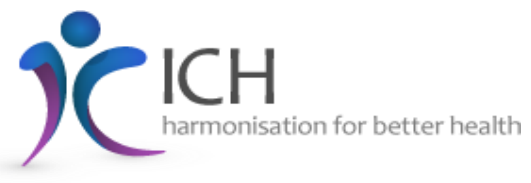

The International Council for Harmonisation of Technical Requirements for Pharmaceuticals for Human Use (ICH) is unique in bringing together the regulatory authorities and pharmaceutical industry to discuss scientific and technical aspects of drug registration. Since its inception in 1990, ICH has gradually evolved, to respond to the increasingly global face of drug development.

On $23^{\text {rd }}$ October 2015 , ICH announced organisational changes as it marks 25 years of successful harmonisation.

\section{Mission of ICH}

- ICH's mission is to achieve greater harmonisation worldwide to ensure that safe, effective, and high quality medicines are developed and registered in the most resource-efficient manner.

- Harmonisation is achieved through the development of ICH Guidelines via a process of scientific consensus with regulatory and industry experts working side-by-side. Key to the success of this process is the commitment of the $\mathrm{ICH}$ regulators to implement the final Guidelines.

- To make recommendations towards achieving greater harmonisation in the interpretation and application of technical guidelines and requirements for pharmaceutical product registration and the maintenance of such registrations.

- To contribute to the protection of public health in the interest of patients from an international perspective.

- To monitor and update harmonised technical requirements leading to a greater mutual acceptance of research and development data.

\section{Organisation of $\mathrm{ICH}$}

Assembly is the overarching body of the Association, composed of all Members that take decisions, regarding Articles of Association, Rules of Procedures, admission of new Members, adoption of ICH Guidelines, etc.

The Management Committee provides recommendations on the selection of new topics for harmonisation as well as on the adoption, withdrawal or amendments of ICH Guidelines. (5)

\section{ICH Guidelines}

\section{a. QUALITY Guidelines}

Harmonisation achievements in the Quality area include pivotal milestones such as the conduct of stability studies, defining relevant thresholds for impurities testing and a more flexible approach to 
pharmaceutical quality based on Good Manufacturing

Practice (GMP) risk management.

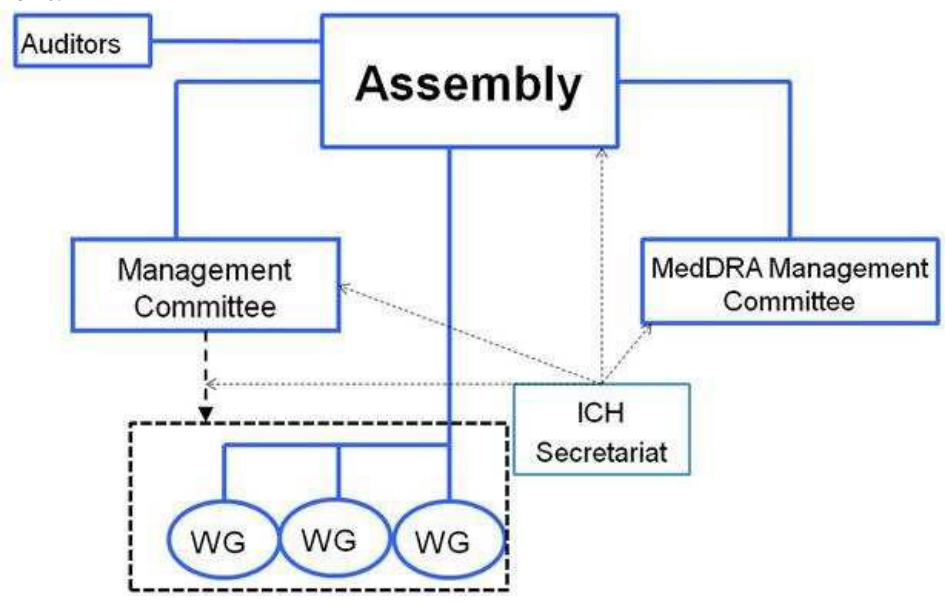

Figure 2. Organisation of ICH (5)

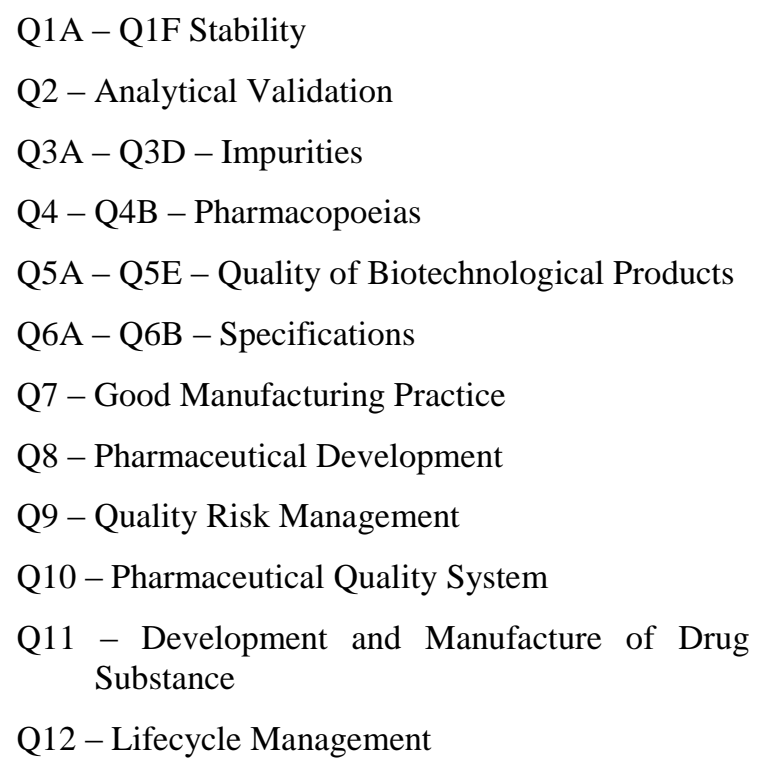

\section{b. SAFETY Guidelines}

ICH has produced a comprehensive set of safety Guidelines to uncover potential risks like carcinogenicity, genotoxicity and reprotoxicity. A recent breakthrough has been a non-clinical testing strategy for assessing the QT interval prolongation liability: the single most important cause of drug withdrawals in recent years.

S1A - S1C - Carcinogenicity Studies

S2 - Genotoxicity Studies

S3A - S3B - Toxicokinetics and Pharmacokinetics

S4 - Toxicity Testing

S5 - Reproductive Toxicology

S6 - Biotechnological Products

S7A - S7B - Pharmacology Studies

S8 - Immunotoxicology Studies

S9 - Nonclinical Evaluation for Anticancer Pharmaceuticals

S10 - Photosafety Evaluation
S11 - Nonclinical Safety Testing

\section{c. EFFICACY Guidelines}

The work carried out by ICH under the Efficacy heading is concerned with the design, conduct, safety and reporting of clinical trials. It also covers novel types of medicines derived from biotechnological processes and the use of pharmacogenetics/genomics techniques to produce better targeted medicines.

E1 - Clinical Safe

E2A - E2F - Pharmacovigilance

E3 - Clinical Study Report

E4 - Dose Response Studies

E5 - Ethinic Factors

E6 - Good Clinical Practice

E7 - Clinical Trials in Geriatric Population

E8 - General Considerations for Clinical Trials

E9 - Statistical Principles for Clinical Trails

E10 - Choice of Control Group in Clinical Trials

E11 - Clinical Trials in Pediatric Popilation

E12 - Clinical Evaluation by Therapeutic Category

E14 - Clinical Evaluation of QT

E15 - Definitions in Pharmacogenetics

E16 - Qualification of Genomic Biomarkers

E17 - Multi-Regional Clinical Trials

E18 - Genomic Sampling

E19 - Safety Data Collection

\section{d. Multidisciplinary Guidelines}

Those are the cross-cutting topics which do not fit uniquely into one of the Quality, Safety and Efficacy categories. It includes the ICH medical terminology (MedDRA), the Common Technical Document (CTD) and the development of Electronic Standards for the Transfer of Regulatory Information (ESTRI). 
M1 - MedDRA Terminology

M2 - Electronic Standards

M3 - Nonclinical Safety Studies

M4 - Common Technical Document (CTD)

M5 -Data Elements and Standards for Drug Dictionaries

M6 - Gene Therapy

M7 - Genotoxic Impurities

M8 - Electronic Common Technical Document (eCTD)

M9 -Biopharmaceutics Classification System-based Biowaivers

M10 -Bioanalytical Method Validation

\section{Food and Drug Administration}

- The Food and Drug Administration (FDA or USFDA) is an agency of the United States Department of Health and Human Services.
- $\quad 1906$ - The original "Pure Food and Drugs Act" is passed by Congress on June 30, 1906 and signed into law by President Theodore Roosevelt

- $\quad$ FDA-regulated products account for about 25 cents of every U.S. dollar (\$) spent by American consumers each year

- FDA has 223 Field Offices and 13 Field Laboratories in the U.S.

\section{Objective of USFDA}

- $\quad$ Protecting the public health by assuring the safety, effectiveness and security of human and veterinary drugs, vaccines and other biological products, medical devices, food, cosmetics, dietary supplements and products that give off radiation.

- Regulating tobacco products.

- Advancing the public health by helping to speed product innovations.

- Helping the public to get accurate science-based information they need to use medicines, devices, and foods to improve their health.

Table 1. What FDA Regulates and What FDA Do Not Regulates

\begin{tabular}{|c|c|}
\hline FDA regulates & FDA does not regulates \\
\hline $\begin{array}{l}\text { - Foods, Food additives, Infant formulas, Bottled } \\
\text { water }\end{array}$ & $\begin{array}{l}\text { - Advertising (except for prescription drugs, } \\
\text { medical devices, and tobacco products). }\end{array}$ \\
\hline - Human prescription and non-prescription drugs & - Alcoholic beverages \\
\hline - Vaccines, Blood products and other Biologics & $\begin{array}{l}\text { - Some consumer products such as paint, child- } \\
\text { resistant packages, Baby toys, and household } \\
\text { appliances (except for those that give off } \\
\text { radiation) }\end{array}$ \\
\hline $\begin{array}{l}\text { Medical devices, from simple items like tongue } \\
\text { depressors, to complex technologies such as heart } \\
\text { pacemakers, dental devices electronic products that } \\
\text { give off radiation, such as microwave ovens and X } \\
\text { ray equipment. }\end{array}$ & $\begin{array}{l}\text { - Illegal drugs of abuse, such as heroin and } \\
\text { marijuana }\end{array}$ \\
\hline - Cosmetics & $\begin{array}{l}\text { - Meat and poultry (except for game meats, } \\
\text { such as venison, ostrich, and snake) }\end{array}$ \\
\hline - Veterinary products & $\begin{array}{l}\text { - Health Insurance } \\
\text { - Pesticides }\end{array}$ \\
\hline - Tobacco products & - Restaurants and grocery stores \\
\hline
\end{tabular}

\section{FDA Organization}

It consists of six product centers, one research center,

Table 2. FDA Structure and two offices. (6-8)

\section{USFDA}

\begin{tabular}{|c|c|}
\hline One research centre: & Six product center: \\
\hline National Cente & 1.Center for Biologics Evaluation and Research \\
\hline Toxicological & (CBER) regulate biological product \\
\hline which supports FD & 2. Center for Devices and Radiological Health \\
\hline $\begin{array}{l}\text { innovative } \\
\text { technology, }\end{array}$ & $\begin{array}{l}\text { 3. Center for Drug Evaluation and Research (CDER) } \\
\text { regulate drug product }\end{array}$ \\
\hline $\begin{array}{l}\text { training, and tech } \\
\text { expertise. }\end{array}$ & $\begin{array}{l}\text { 4. Center for Food Safety and Applied Nutrition } \\
\text { (CFSAN) regulates food product }\end{array}$ \\
\hline & $\begin{array}{l}\text { 5. Center for Tobacco Products, which regulates } \\
\text { tobacco product } \\
\text { 6. Center for Veterinary Medicine (CVM) which }\end{array}$ \\
\hline
\end{tabular}

\section{Two offices:}

1. Office of Regulatory Affairs: which conducts inspections and enforces FDA regulations

2. Office of the Commissioner: which provides leadership and direction to FDA's product centers, research center, and Office of Regulatory Affairs. 
regulates feed and drugs and devices used in pets,

farm animals, and other animals

\section{European Medicines Agency}

The European Medicines Agency (EMA) is a European Union agency for the evaluation of medicinal products. Prior to 2004, it was known as the European Agency for the Evaluation of Medicinal Products (EMEA).
The European Medicines Agency (or EMA) is the regulatory body in Europe that ensures that medicines are safe and that they work as expected. Agency is Located in London, the Agency is responsible for both human and veterinary medicines and has an important role in protecting public health in the EU.

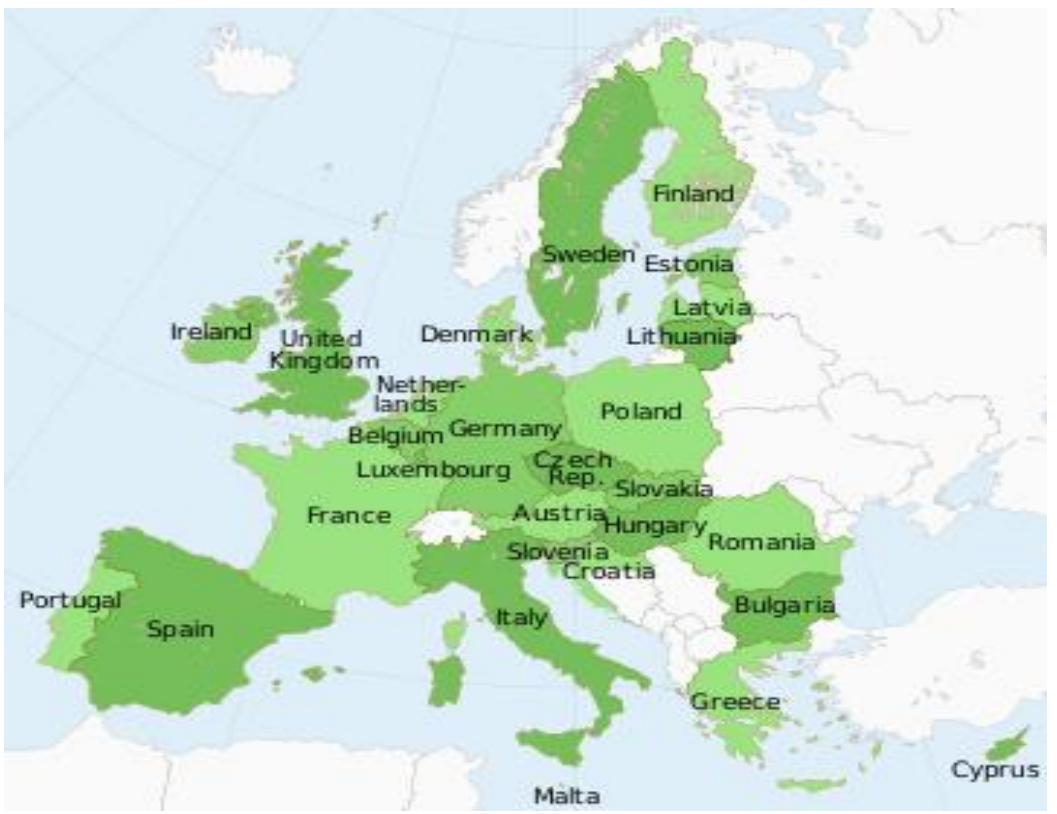

Figure 3. Member states of European Union (6)

Working together with the national authorities of the 28 EU Member States as well as the Agency is key part of the European regulatory system for medicines. This collaborative model is the basis of the Agency's success as it gives the Agency access to a pool of experts (including regulators, academics, patients and healthcare professionals) from across the EU, giving it access to the best available scientific expertise. (9)

\section{EMA Organization}

The EMA is an Agency of the EU, In addition to the MS and the 4,500 European experts we have available to us, we work closely with the European Commission and

Table 3. What EMA Regulates and What EMA Do Not Regulates the European Parliament as well as a number of other EU Agencies.

The Agency is governed by its Management Board composed of representatives of the MS, the Parliament and the Commission. The role of the Board is to adopt implementing rules and to set the strategic direction for the work of the Agency.

The European regulatory system for medicines is a unique model in the global regulatory environment. EMA working closely together with member state in an integrated fashion.
EMA regulates

- The Agency's main responsibility is the protection and promotion of public and animal health, by carrying out scientific evaluations of medicines for human and veterinary use.

- We also supervise the safety of medicines in the EU after they have been authorised. It can also give scientific opinions on medicines at the request of Member States or the European Commission.

\section{EMA does not regulates}

The EMA does not control:

- Pricing of medicines

- Access to medicines

- Advertising of medicines

- Patents on medicines

- Medical devices

- Homoeopathic medicines

- Food supplements

- Cosmetics

\section{Parenteral Product}

\section{Advantages of Parenteral products}

> Useful for patients who cannot take drugs orally.

$>$ Rapid onset of action

$>$ Useful for emergency situations.
$>$ Providing sustained drug delivery (implants, im depot inj).

$>$ Avoid first pass metabolism

$>$ Can inject drug directly in to a tissue (target drug delivery). 
> Useful for delivering fluids, electrolytes, or nutrients (TPN).

$>$ Can be done in hospitals, ambulatory infusion centers and home health care centers.

$>$ Complete bioavailability.

\section{Disadvantages of Parenteral products}

$>$ Pain on injection

$>$ Difficult to reverse an administered drug's effect.

$>$ Sensitivity or allergic reaction at the site of injection.

$>$ Requires strict control of sterility \& non pyrogenicity than other formulation.

$>$ Trained person is required.

$>$ Require specialized equipment, devices, and techniques to prepare and administer drugs.

$>$ More expensive and costly to produce.

Types of the parenteral products

Table 4. Difference between SVP \& LVP a. Small volume parenterals (SVP):

$>$ An injection that is packed in containers labeled as containing less than $100 \mathrm{ml}$ is known as small volume parenterals (SVP), this definition is as per USP, EP, BP.

$>$ While as per IP $100 \mathrm{ml}$ labeled container is not consider in SVP.

b. Large volume parenterals (LVP):

$>$ An injection that is packed in containers labeled as containing $100 \mathrm{ml}$ or more is known as large volume parenterals (LVP), this definition is as per USP, EP, BP,IP.

$>$ Products like Dextrose injection I.P., Sodium Chloride injection I.P., Ciprofloxacin injection USP etc.

\begin{tabular}{|c|c|c|}
\hline Parameter & SVP & LVP \\
\hline Volume & $100 \mathrm{ml}$ or less & $101-1000 \mathrm{ml}$ \\
\hline Routes & IV, IM, SC & IV-LVP \& non IV-LVP \\
\hline Dosage unit & Single or multiple & Single \\
\hline Preservative & Used & Not used \\
\hline Buffers & Used & Not used \\
\hline Formulation & Solution, Emulsion, Suspension & $\begin{array}{l}\text { Solution } \\
\text { emulsion }\end{array}$ \\
\hline Isotonicity & Not essential & Must \\
\hline Pyrogenicity & Not essential & Must \\
\hline Use & Therapeutic \& diagnostic & $\begin{array}{l}\text { Nutrition, detoxification, and } \\
\text { during surgery }\end{array}$ \\
\hline
\end{tabular}

\section{Formulation}

Aqueous vehicle - Water for Injection

Highly purified water used as a vehicle for injective preparations which will be subsequently sterilized. As per USP requirement include not more than 10 parts per million of total solids. It is clear, colorless, odourless and pyrogen free.

WFI may be prepared by either distillation or reverse osmosis and stored in chemically resistant tank to prevent the growth of microorganism and to avoid any other contamination. WFI has $\mathrm{P}^{\mathrm{H}} 5.0$ - 7.0. (10)

7. Introduction of post approval changes and variation guideline in USA and EUROPE

\section{"Products Rarely Stay the Same"}

During their life cycle, medicinal products are generally having many changes. The product rarely stays the same in original (Registered) condition. The driving forces for these changes are manifold, e.g., the need to introduce process and production improvements, market demands, the continuously evolving requirements of regulatory bodies. There are many reasons for making change to pharmaceutical products after the original regulatory approval is obtained. For each change, it is necessary to find out the acceptability of the proposed changes, in order to prove that the specified change does not have an adverse effect on the product. Some of these changes may be significant and require a substantial amount of stability data while others are minor and may only require a stability commitment. The type of change will dictate the amount of data needed and the type of regulatory reporting required. The company change control is used to determine detail how changes are evaluated and implemented and how the change impacts stability. The regulatory group determines the strategy which may be more complex if the product is marketed globally and this strategy made for submission based on review of the technical assessment of the change and the appropriate regulatory guidance.

"Once a product is commercialized, at some point in its life cycle, something will change.

\section{Product Life Cycle}

Guidance documents provide direction on the reporting category for different types of changes. Different type of guideline by different authorities are provides separate study design or data package for each changes. It may be a significant change to the formulation or to the active pharmaceutical ingredient, or it may be relatively minor changes, such as extending the expiration date or changing a test method as technology improves. Whatever the modification, the key to any change is to understand the impact that the changes will have on safety and efficacy of the product. For that the right studies required to maximize the value of the data in order to demonstrate the impact-of the 
changes on the product. This study concern about which regulatory requirement or regulatory notification

required, and technical data required for each changes and additional guidance for post approval changes.

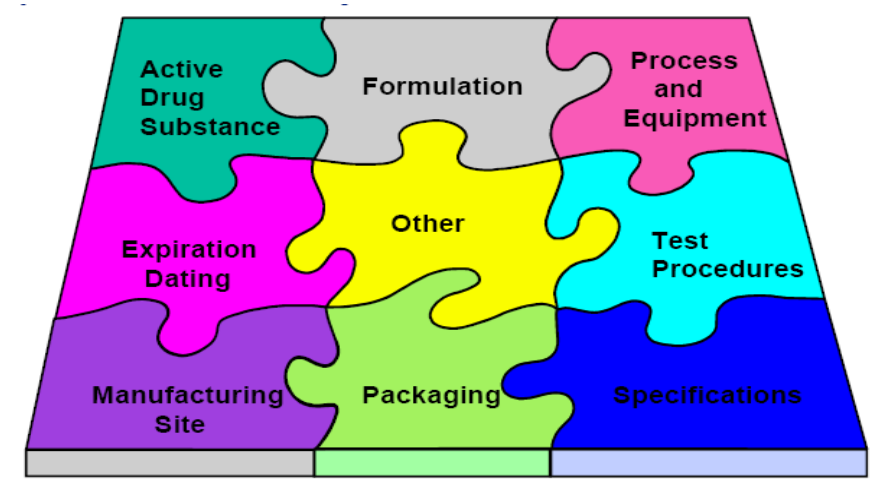

Figure 4. Product Life Cycle

These additional guidance documents are extremely helpful in identifying:

- $\quad$ Specific type of changes.

- The classification of the specific changes (Minor, Moderate, Major).

- The data needed to evaluate the specific changes.

This additional detail allows reporting that reflects the levels of risk associated with specific changes.

\section{Types of Post Approval Changes and variation guideline for USA}

The post approval changes are to be in accordance with section 506A of the Federal Food, Drug, and Cosmetic Act (the Act) and $\S 314.70$ (21 CFR 314.70). The post approval changes are categorically reported as
a) Major changes
b) Moderate changes.
c) Minor changes.

\section{a. Major change}

A major change is a change that has a substantial potential to have an adverse effect on the identity, strength, quality, purity, or potency of a drug product as these factors may relate to the safety or effectiveness of the drug product. A major change requires the submission of a Supplement and approval by FDA prior to distribution of the drug product made using the change.

This type of supplement is called, and should be clearly labelled, a "Prior Approval Supplement". An applicant may ask FDA to expedite its review of a prior approval supplement for public health reasons (e.g., drug shortage) or if a delay in making the change described in it would impose an extraordinary hardship on the applicant. This type of supplement is called, and should be clearly labelled, a "Prior Approval Supplement Expedited Review Requested". FDA is most likely to grant requests for expedited review based on extraordinary hardship for manufacturing changes made necessary by catastrophic events (e.g., fire) or by events that could not be reasonably foreseen and for which the applicant could not plan.

\section{b. Moderate change}

A moderate change is a change that has a moderate potential to have an adverse effect on the identity, strength, quality, purity, or potency of the drug product as these factors may relate to the safety or effectiveness of the drug product.

There are two types of moderate change. One type of Moderate change requires the submission of a supplement to FDA at least 30 days before the distribution of the drug product made using the change. This type of supplement is called, and should be clearly labeled, a "Supplement - Changes Being Effected in 30 Days". The drug product made using a moderate change cannot be distributed if FDA informs the applicant within 30 days of receipt of the supplement that a prior approval supplement is required. For each change, the supplement must contain information determined by FDA to be appropriate and must include the information developed by the applicant in assessing the effects of the change. If FDA informs the applicant within 30 days of receipt of the supplement that information is missing, distribution must be delayed until the Supplement has been amended to provide the missing information. FDA may identify certain moderate changes for which distribution can occur when FDA receives the supplement. This type of supplement is called, and should be clearly labelled, a "Supplement - Changes Being Effected". If, after review, FDA disapproves changes-being effected-in-30-days supplement or changes-being-effected supplement.

\section{c. Minor change}

Minor change is a change that has minimal potential to have an adverse effect on the identity, strength, quality, purity, or potency of the drug product as these factors may relate to the safety or effectiveness of the drug product. The applicant must describe minor changes in its next Annual Report. Under § 314.70(e), an applicant can submit one or more protocols (i.e., comparability protocols) describing tests, studies, and acceptance criteria to be achieved to demonstrate the absence of an adverse effect from specified types of changes. A comparability protocol can be used to reduce the reporting category for specified changes. A proposed comparability protocol that was not approved as part of 
the original application must be submitted as a prior

Table 5. Types of Post Approval Changes in USA approval supplement.

\begin{tabular}{|c|c|c|c|}
\hline Parameters & $\begin{array}{c}\text { Major } \\
\text { PAS(Prior Approval } \\
\text { Supplement) }\end{array}$ & $\begin{array}{c}\text { Moderate } \\
\text { CBE 30(Changes } \\
\text { Being Effected in } 30 \\
\text { days) }\end{array}$ & \begin{tabular}{l}
\multicolumn{1}{c}{ Minor } \\
CBE 0(Changes Being \\
Effected in 0 day $)$
\end{tabular} \\
\hline Definition & $\begin{array}{l}\text { Changes that drastically } \\
\text { alters the efficacy and } \\
\text { safety profile of the drug. }\end{array}$ & $\begin{array}{l}\text { Changes that moderately } \\
\text { modify the safety and } \\
\text { efficacy of the drug. }\end{array}$ & $\begin{array}{l}\text { Changes that slightly modify } \\
\text { the efficacy and safety of the } \\
\text { drug but almost harmless. }\end{array}$ \\
\hline Approval Status & $\begin{array}{l}\text { Prior approval of FDA } \\
\text { required to implement the } \\
\text { change. }\end{array}$ & $\begin{array}{l}\text { FDA is informed about } \\
\text { the changes, needs } \\
\text { approval within } 30 \text { days. }\end{array}$ & $\begin{array}{l}\text { No need of any prior } \\
\text { approvals for the changes } \\
\text { intended. }\end{array}$ \\
\hline $\begin{array}{l}\text { Release and } \\
\text { Distribution }\end{array}$ & $\begin{array}{l}\text { Approval by FDA prior to } \\
\text { distribution of the drug } \\
\text { product made using the } \\
\text { change is mandatory. }\end{array}$ & 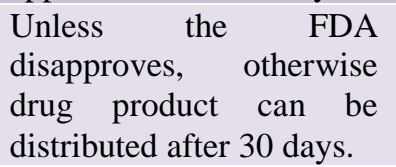 & $\begin{array}{l}\text { The drug product can be } \\
\text { distributed, but the changes } \\
\text { are to be clearly mentioned in } \\
\text { the annual report. }\end{array}$ \\
\hline Documentation & $\begin{array}{l}\text { Needs prior approval } \\
\text { supplement and changes } \\
\text { done to be notified in the } \\
\text { annual report. }\end{array}$ & $\begin{array}{l}\text { Need Supplement - } \\
\text { Changes Being Effected } \\
\text { in } 30 \text { Days and } \\
\text { Supplement - Changes } \\
\text { Being Effected }\end{array}$ & $\begin{array}{l}\text { Documented in the product } \\
\text { annual report. }\end{array}$ \\
\hline
\end{tabular}

\section{The Greater The Risk Is, The Greater The Filing Requirement}

In many cases, this allows for a lower reporting requirement than is recommended in the more general guidance documents because changes that were grouped together into more general categories would be evaluated individually.

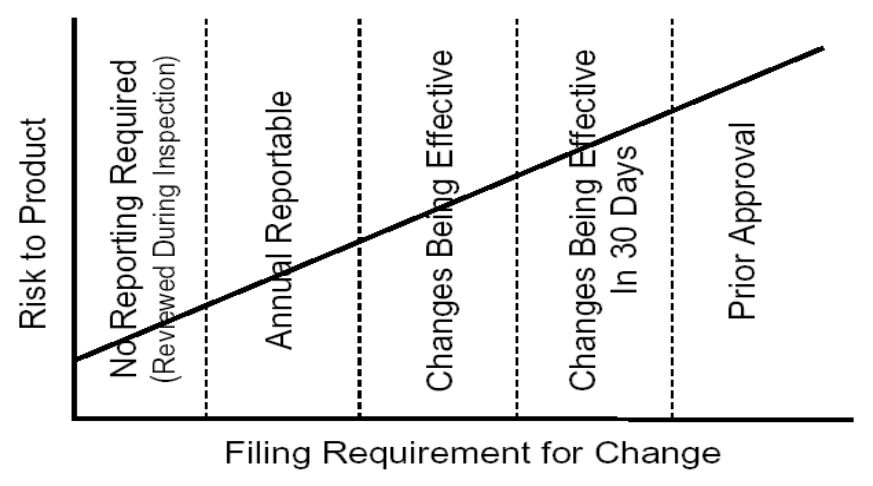

Figure 5. Risk assessment of Variation filing

\section{Annual Report}

As per US CFR 314.70 regulations, the applicant must notify USFDA about each change in each condition established in an approved application beyond the variations already provided for in the application. Depending on the type of change, the applicant must notify USFDA about the change in a supplement or variation under 21 CFR 314.70 paragraph (b) or (c) or by inclusion of the information in the AR to the application under 21 CFR 314.70 paragraph (d).

Each Annual Report is required to be accompanied by a completed transmittal Form FDA 2252 (Transmittal of Periodic Reports for Drugs for Human Use), and must include all the information required under this section that the applicant received or otherwise obtained during the annual reporting period that ends on the U.S. anniversary date i.e. approval date of the drug product with US FDA.
The AR reporting period is considered as 1 year from starting to the date of approval to the next year same anniversary date. Each AR should be submitted within 60 days from the due U.S. anniversary date of the drug product, of each subsequent year after receipt of approval from USFDA. The reportability to Annual Report is assessed on a case to case basis using USA variation guidance.

All Annual Report submissions in US is done through US local agent only, Company is not able to submit Annual Report without US local agent. If company is USA based then not required any local agent.

\section{Variation/Supplement Submission in USA}

To define the process and steps to be followed for the preparation of variation/ supplement as well as amendment application in electronic Common Technical Document (eCTD) format for US Food Drug and Administration (FDA) according to the guideline on 
Variation- Changes to an approved NDA or ANDA to obtain the regulatory approval in US.

\section{eCTD format}

The eCTD is defined as an interface for industry to agency transfer of regulatory information while at the same time taking into consideration the facilitation of the creation, review, lifecycle management and archival of the electronic submission. The eCTD specification lists the criteria that will make an electronic submission technically valid. The focus of the specification is to provide the ability to transfer the registration application electronically from industry to a regulatory authority. Industry to industry and agency to agency transfer is not addressed.

The specification for the eCTD is based upon content defined within the CTD issued by the ICH M4. The structure and level of detail specified in the CTD have been used as the basis for defining the eCTD structure and content but where appropriate, additional details have been developed within the eCTD specification. The philosophy of the eCTD is to use open standards. Open standards, including proprietary standards, which through their widespread use can be considered de facto standards, are deemed to be appropriate in general.

\section{Scope}

The CTD as defined by the M4 EWG does not cover the full submission that is to be made in a region. It describes only modules 2 to 5 , which are common across all regions. The CTD does not describe the content of module 1, the Regional Administrative Information and Prescribing Information, nor does it describe documents that can be submitted as amendments or variations to the initial application.

The value of producing a specification for the creation of an electronic submission based only upon the modules described in the CTD would be limited. Therefore, the M2 EWG has produced a specification for the eCTD that is applicable to all modules of initial registration applications and for other submissions of information throughout the lifecycle of the product, such as variations and amendments.

This document describes the parts of the registration application that are common to all regions and some of the lifecycle requirements for products. The parts of the registration application that are specific to a region will be covered by regional guidance. However, this backbone has been developed to handle both the regional and common parts of submissions.

\section{Requirements}

The specification is designed to support high-level functional requirements such as the following:

- Viewing and printing of documents

- Annotation of documentation

- Facilitate the exporting of information to databases

- Searching within and across applications
- Navigation throughout the eCTD and its subsequent amendments/variations.

\section{Types of Post Approval Changes and variation guideline for Europe}

Commission Regulation (EC) No 1234/2008 of 24 of November 2008, concerning the examination of variations to the terms of marketing authorizations for medicinal products for human use and veterinary medicinal products, ('the Variations Regulation'), governs the procedure for the variation of marketing authorizations. It has been amended by Regulation (EU) $712 / 2012$.

These guidelines apply to the variations of marketing authorizations for medicinal products for human use and veterinary medicinal products granted in accordance with Regulation726/2004, Directive 2001/82, Directive 2001/83 and Council Directive 87/223. They are intended to facilitate the interpretation and application of the Variations Regulation. They provide details on the application of the relevant procedures, including a description of all the relevant steps from the submission of an application for a variation to the final outcome of the procedure on the application.

These guidelines cover the following categories of variations, defined in Article 2 of the

Variations Regulation:

- Minor variations of Type IA

- Minor variations of Type IB

- Major variations of Type II

- Extensions

- Urgent safety restriction

The reference Member State, the national competent authority or the Agency is available to address any questions which holders may have regarding a particular upcoming variation. Where appropriate, a presubmission discussion may be organized with the reference Member State, the national competent authority or the Agency in order to obtain further regulatory and procedural advice

\section{Minor variations of Type IA}

Minor variations do not require any prior approval, but must be notified by the holder within 12 months following implementation ("Do and Tell" procedure). However, certain minor variations of Type IA require immediate notification after implementation, in order to ensure the continuous supervision of the medicinal product.It is called as Type IAin (Immediate notification).

\section{Minor variations of Type IB}

Such minor variations must be notified before implementation. The holder must wait a period of 30 days to ensure that the notification is deemed acceptable by the relevant authorities before implementing the change ("Tell, Wait and Do" procedure). 


\section{Major variations of Type II}

Such major variations require approval of the relevant competent authority before implementation.

Notifications for major variations of Type II must be submitted by the holder simultaneously to all Member States concerned, to the national competent authority or to the Agency (as appropriate).

\section{Extensions}

Annex I of the Variations Regulation sets out a list of changes to be considered as extensions. As established in Article 19 of the Variations Regulation, such applications will be evaluated in accordance with the same procedure as for the granting of the initial marketing authorization to which it relates. The extension can either be granted as a new marketing authorization or will be included in the initial marketing authorization to which it relates.

Extension applications must be submitted to all Member States concerned, to the national competent authority, or to the Agency (as appropriate).

\section{Urgent Safety Restrictions}

Article 22 of the Variations Regulation foresees that in the event of a risk to public health in the case of medicinal products for human use or in the event of a risk to human or animal health or to the environment in the case of veterinary medicinal products, the holder may take provisional "urgent safety restrictions".

Urgent safety restrictions concern interim change(s) in the terms of the marketing authorization due to new information having a bearing on the safe use of the medicinal product. These urgent changes must be subsequently introduced via a corresponding variation in the marketing authorization.

The holder must immediately notify all Member States concerned, the national competent authority or the Agency (as appropriate) of the restrictions to be introduced. (11-14)

\section{Gateway of filing variation to regulatory authority}

This procedure is applicable to all the variation / supplement applications for all the approved generic products.

\section{Variation Submission in Europe}

This procedure is applicable for the submission of variation applications for all the products approved via national, MRP (Mutual Recognition Procedure) and DCP (Decentralised Procedures) to regulatory partner or regulatory authority.

\section{Objective}

The objective of this procedure is to describe the best practice for the preparation, submission and processing of variation applications in Europe, in line with Coordination Group for Mutual Recognition and Decentralised Procedures (CMDh) guideline.
To define the process and steps to be followed for the preparation of variation application in electronic Common Technical Document (eCTD) format or NoneCTD electronic Submission (NeeS).

Prepared package will be submitted by Common European Submission Portal (CESP) for European Medicine Agency (EMA) according to the guideline on Variation- post approval change management protocols.

\section{Common European Submission Portal}

This system provides a simple and secure mechanism for exchange of information between applicants and regulatory agencies.

The purpose of the system is to:

- Provide a secure method of communicating with the Regulatory Agencies via one platform.

- Allow submission of an application once to reach all required Agencies.

- Reduce the burden for both Industry and Regulators of submitting/handling applications on CD-ROM and DVD.

Each company must have a least one company administrator which will be setup during the registration process by the CESP support team. Once the company registration has been approved, the nominated company administrator will receive connection details to their registered email address. The company administrator is then responsible for setting up additional companies/users on the system as required. There is no charge to use the system. $(2,15,16)$

\section{Structure of eCTD}

\section{File Names and Directory Structure}

Recipients of the eCTD should be able to directly navigate through the submission at the folder and file level (i.e., without benefit of a customized end user application.) The structure of the eCTD and instructions for how to create folder names facilitate this type of navigation.

In order to preserve the navigational linkages that can be present in the documents contained in the eCTD, the directory structure should be preserved by the agencies. The navigational links should be relative links within a module.

The top level of the directory structure will vary by region. The identification of the top-level folder uniquely identifies the submission in a region. The submission identification should be used as the folder name in the top-level directory. For example, if the submission number were NDA-123456, the root directory would be named "nda-123456". The original submission and subsequent amendments and variations should use the same top-level folder name. Submissions should be differentiated by a subfolder named according to the sequence number of the submission in that region. 
Table 6. Illustrate the naming convention

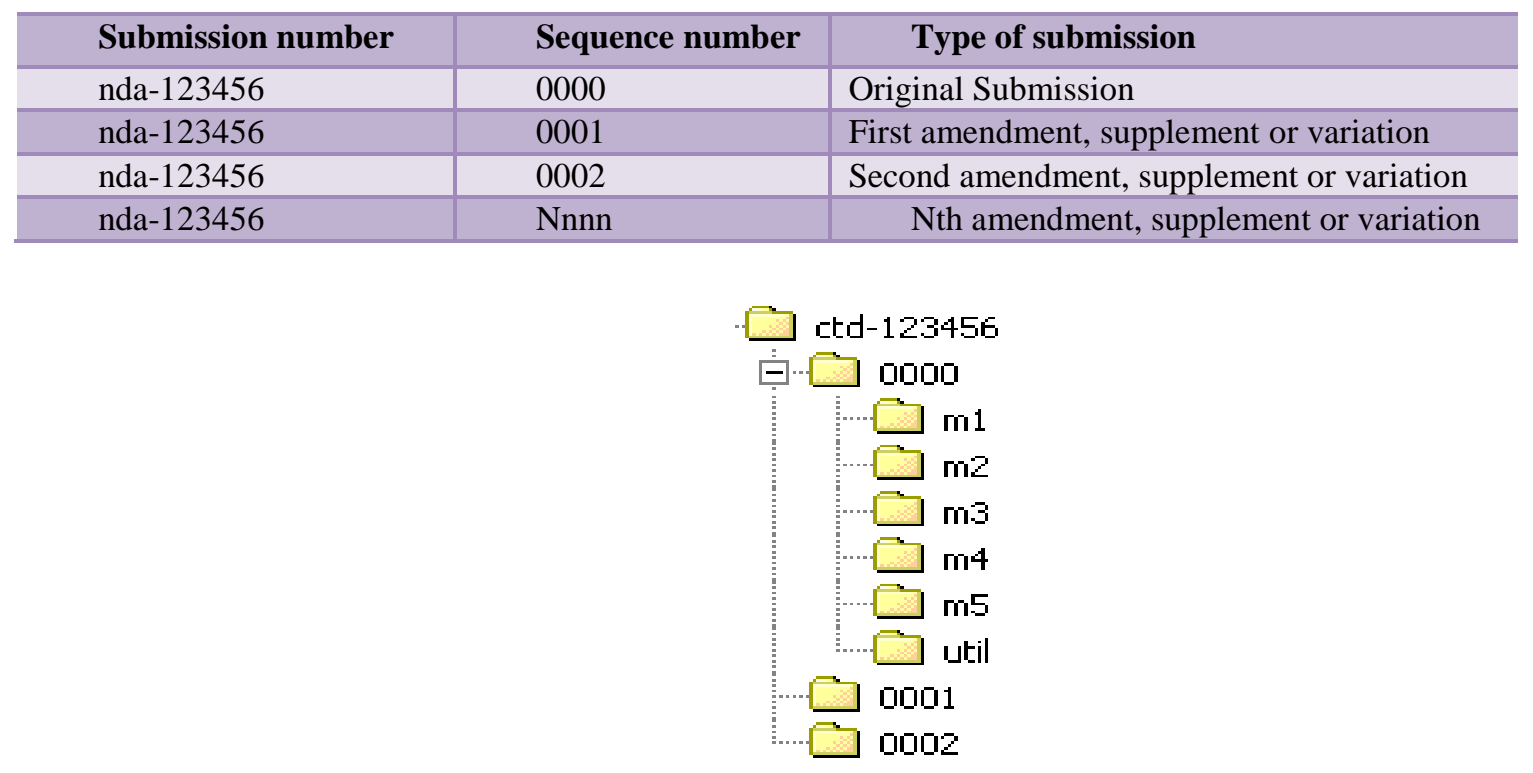

Figure 6. Illustrate the naming convention (6)

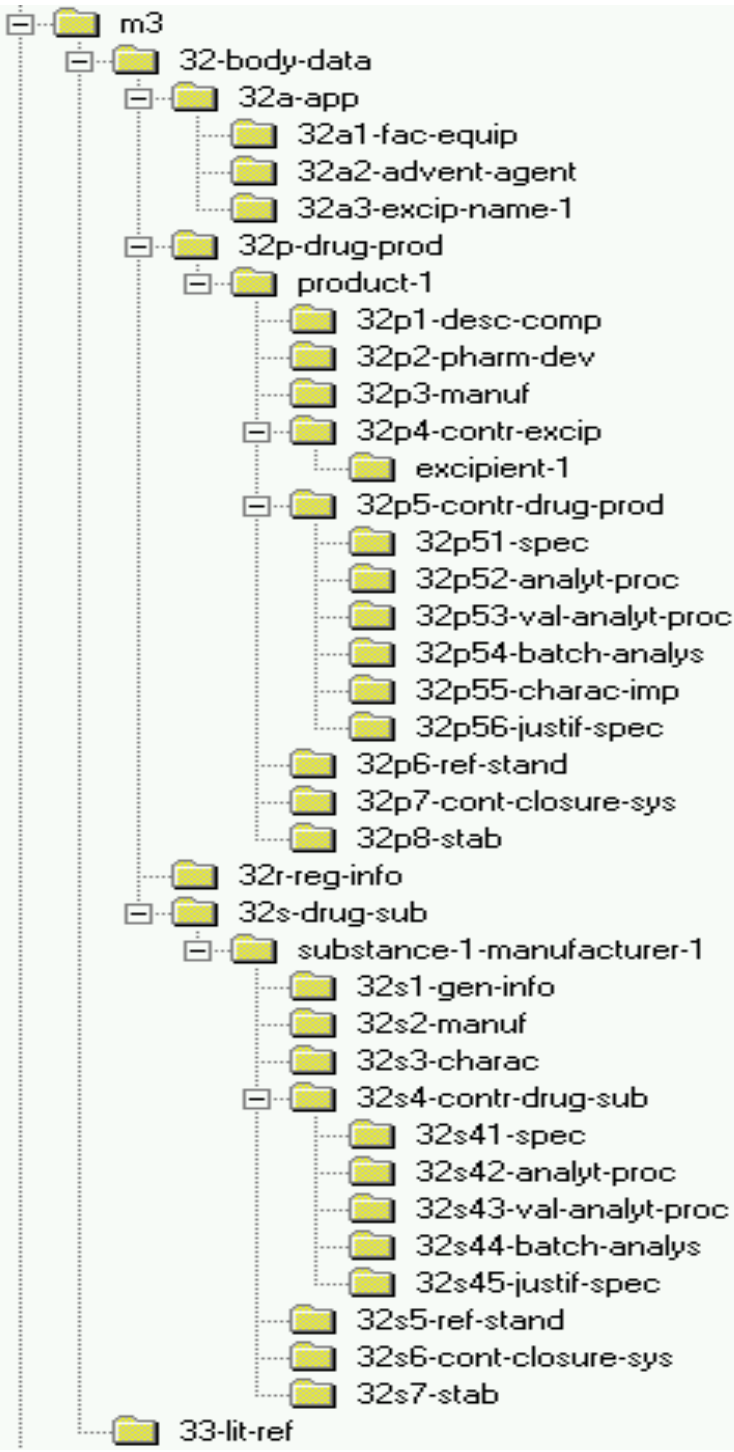

Figure 7. Screenshot of the folder structure of module 3 (6) 


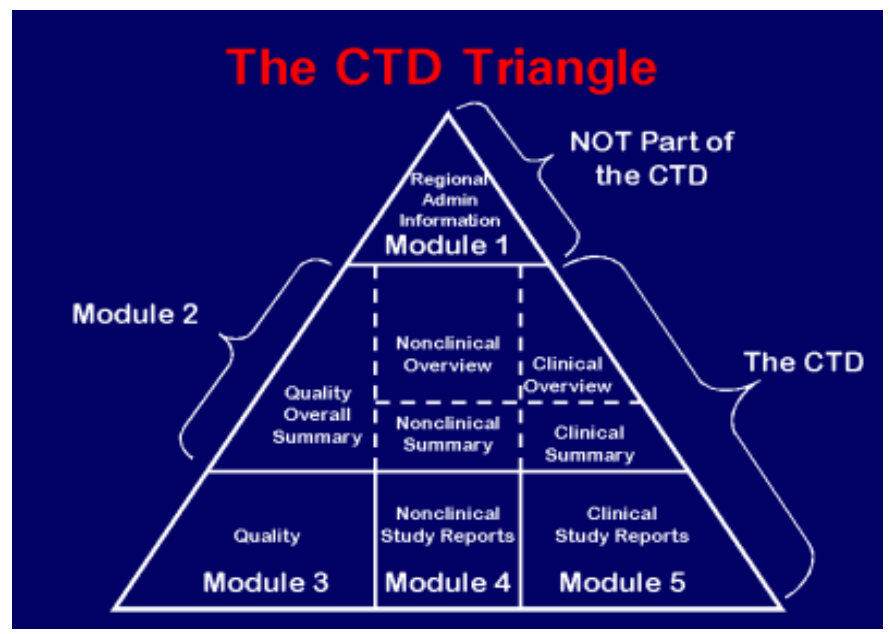

Figure 8. The CTD Triangle (6)

\section{Conclusion}

After reviewing EU and US FDA's post approval activities (supplement/variation), it can be concluded that both the agencies have identical submission pattern. Changes which are classified as Minor can be notified as Annual Reportable Changes in US, while in EU Type IA variation is required wherein such changes are notified to agency within 1 year of implementation. It can be said as "Do and tell". For minor/moderate changes where immediate notification is required, such changes can be submitted to US FDA via CBE-0 submission; while in EU Type IAin (immediate notification) can be submitted. It is called as "Do and immediately tell". For Moderate changes, like change in CMC (Chemistry, Manufacturing, Control), CBE-30 supplement is required. For EU Type IB variation is required. After notify agency, the applicant has to wait for at least 30 days before implementing such changes. If agency does not ask for additional data for 30 days, then the applicant can implement such changes. Such changes are called as "Tell, wait and do". However, if agency asks for any additional data, then the applicant cannot implement such changes until regulatory agency gives approval or confirmation to applicant through appropriate communication channel (via e-mail or formal approval letter). For changes which are classified as Major, prior approval is required. The applicant has to submit PAS supplement to US FDA, while in EU Type II variation is required. The applicant cannot implement such changes until regulatory agency gives approval. Such changes are called as "Prior Approval Supplement".

Regarding the timeline or review cycle, approval is received within 30 days after notifying Type IA or IAin variation to EU agency. FDA does not provide approval for Annual Reportable Changes. For Type IB, generally 30 days review cycle is required by agency. However additional 30 days 2 nd cycle review is required if agency request the applicant for additional data or clarification. US agency generally gives approval within 30 days from the date of notification. For approval of Type II variation, in EU 90 to 120 days review cycle is required. However, the applicant generally receives approval within 6-9 months. For US, 10 months review cycle is required by the FDA agency.

\section{Acknowledgements}

The Author and co-author, thanks to Saraswati Institute of Pharmaceutical Sciences, for providing the necessary facility to accomplish the work we also humble gratitude to our colleague and non-teaching staff for their support during the work.

Financial Disclosure statement:The authors received no specific funding for this work.

\section{Conflict of Interest}

The authors declare that there is no conflict of interest regarding the publication of this article.

\section{References}

1. Pankaj K, Eshant D, Parveen B and Jitendra B. "Marketing Authorization of Generic Drug: Global Issue And Challenges", Int. J. Drug Regulatory Affairs. 2013;1(3):1-6.

2. Joseph L,George M, Kalpesh M, Bincy C and Jitendra B. "Comparative Study for Generic Drug Approval Process and their Registration as per CTD in Europe, USA and Brazil", Int. J. Drug Regulatory Affairs. 2016;4(2):1-9.

3. Lakshmi M, "Advances in the Review of Generic Drug Applications by United States Food And Drug Administration, A Regulatory Perspective in The Era Of GDUFA (Generic Drug User Fee Amendment 2012)”, Int. J. Drug Regulatory Affairs. 2015;3(1): 41-61.

4. Philip S, "The Scope of Regulatory Affairs in the Pharmaceutical Industry" Hygeia. J.D.Med. 2010;1-6.

5. "ICH Official web site : ICH [Internet]. ICH; 2021 [cited 2021 May 15]. Available from:

http://www.ich.org/home.html

6. Fda.gov. What does FDA regulate? [Internet]. FDA; 2020 Mar 08 [cited 2021 May 15]. Available from: http://www.fda.gov/AboutFDA/Transparency/Basics/ucm 194879.htm

7. Uky.edu. [Internet]. research.uky [cited 2021 May 15]. Available from:

http://www.research.uky.edu/ori/ORIForms/D116-FDAResources.pdf

8. Office of the Commissioner. U.S. Food and Drug Administration [Internet]. FDA; 2021 [cited 2021 May 15]. Available from:

https://www.fda.gov/default.htm

9. Europa.eu. [Internet]. EMEA; 2021 [cited 2021 May 12]. Available from:

http://www.ema.europa.eu/ema/index.jsp?curl=pages/hom e/Home_Page.jsp\&mid 
10. Europa.eu. [Internet]. EMEA; 2021 [cited 2021 May 15]. Available from:

https://ec.europa.eu/health/sites/health/files/files/eudralex/ vol.

11. Fda.gov. Changes to an Approved NDA or ANDA. Guidance for Industry [Internet]. FDA; 2004 Apr [cited 2021 May 12]. Available from:

https://www.fda.gov/downloads/drugs/guidancecomplianc eregulatoryinformation/guidances/ucm077097.pdf

12. Health USD, Services H. Guideline for Submitting Documentation for the Manufacture of and Controls for Drug Products. Food and Drug Administration. 1987;1-6.

13. Krishna G, "Post Approval Regulatory Requirements for A New Drug Application (NDA)", Am. J. PharmTech Res. 2013;3(1).

14. Anu K and Vivek C, "Recent Review on Parenteral Products - Sterile Dosage Form", IJARIIE. 2017; 3(1).

15. Vishal P, Rahulgiri G, Pratik M, and Jitendra B. A Review On Drug Approval Process For US, Europe and India. Int. J. Drug Regulatory Affairs. 2014; 2(1):1-11.

16. FDA.gov. M4: The CTD -- General Questions and Answers [Internet]. FDA; 2004 Dec [cited 2021 May 10]. Available from:

https://www.fda.gov/downloads/Drugs/GuidanceComplia nceRegulatoryInformation/Guidances/UCM073276.pdf 